\title{
Suffocation due to Thoracic Deformity Caused by Acromegaly
}

\author{
Toshihiko Yoshizawa ${ }^{1}$, Masayuki Iwazaki ${ }^{2}$, Kei Jitsuiki ${ }^{1}$, Kouhei Ishikawa ${ }^{1}$, \\ Hiromichi Ohsaka ${ }^{1}$ and Youichi Yanagawa ${ }^{1}$
}

\begin{abstract}
A 61-year-old man with gigantism and acromegaly choked and fell into a coma. Immediate tracheal intubation resulted in a return of his consciousness. Enhanced computed tomography indicated that the trachea and left main bronchus were compressed by the thoracic spine and sternum. He required tracheotomy and positive end-expiratory pressure to maintain his pulmonary function. This is the first case of suffocation due to a thoracic deformity associated with acromegaly. Physicians should focus on clearing the tracheal airway using computed tomography to elucidate the anatomical relationship between the trachea and surrounding structures in acromegalic patients suffering from dyspnea.
\end{abstract}

Key words: suffocation, thoracic deformity, acromegaly

(Intern Med 56: 949-951, 2017)

(DOI: 10.2169/internalmedicine.56.7615)

\section{Introduction}

The causes of suffocation induced by airway obstruction include foreign objects, sputum, blood, vomiting material, allergic reaction, trauma, airway inflammation (including abscess), tumors, vascular issues, collapse of the airway wall (tracheomalacia or bronchomalacia), or chronic obstructive pulmonary disease (1). Suffocation may also be induced by a thoracic deformity due to compression of the trachea by the thoracic spine and sternum. Grillo et al. reported four adult patients who had tracheal compression caused by straight back syndrome, chest wall deformity, and anterior spinal displacement (2). In addition, Andrews et al. and Donnelly and Bisset reported abnormalities of the bony thorax causing tracheobronchial compression in children $(3,4)$. In Japan, we identified five cases of tracheal compression that were complicated with cerebral palsy, which could induce thoracic deformities (5-9).

In patients with acromegaly, the rate of death due to respiratory causes is three times higher than that in the general population and is most often caused by upper airway obstruction $(10,11)$. The upper airway obstruction in patients with acromegaly is generally considered to be caused by macroglossia and pharyngeal soft tissue hypertrophy and is rarely due to tracheal compression by thyroid swelling or the induction of bilateral paralysis of the vocal cord by nerve palsy due to soft tissue hypertrophy (10-15). In such cases, simple tracheotomy can achieve a favorable outcome. We herein report the first case of suffocation induced by an acromegalic thoracic deformity.

\section{Case Report}

A 61-year-old man admitted to the orthopedic ward for treatment of right artificial hip joint malfunction had complained of dyspnea, showed choking signs, had a low percutaneous oxygen saturation $\left(\mathrm{SpO}_{2}\right)(50 \%)$, and fell into a coma. Immediate tracheal intubation and back bulb ventilation resulted in a return of his consciousness. Sputum production was not confirmed by tracheal tube suction. On the same day, accidental self-extubation resulted in the reoccurrence of signs of upper airway obstruction, thus he underwent repeated tracheal intubation following deep sedation. At 36 years of age, the patient had undergone transcranial subtotal resection of a pituitary tumor following a diagnosis

${ }^{1}$ Department of Acute Critical Care Medicine, Shizuoka Hospital, Juntendo University, Japan and ${ }^{2}$ Department of Respiratory Surgery, Tokai University, Japan

Received for publication April 22, 2016; Accepted for publication August 29, 2016

Correspondence to Dr. Youichi Yanagawa, yyanaga@juntendo.ac.jp 


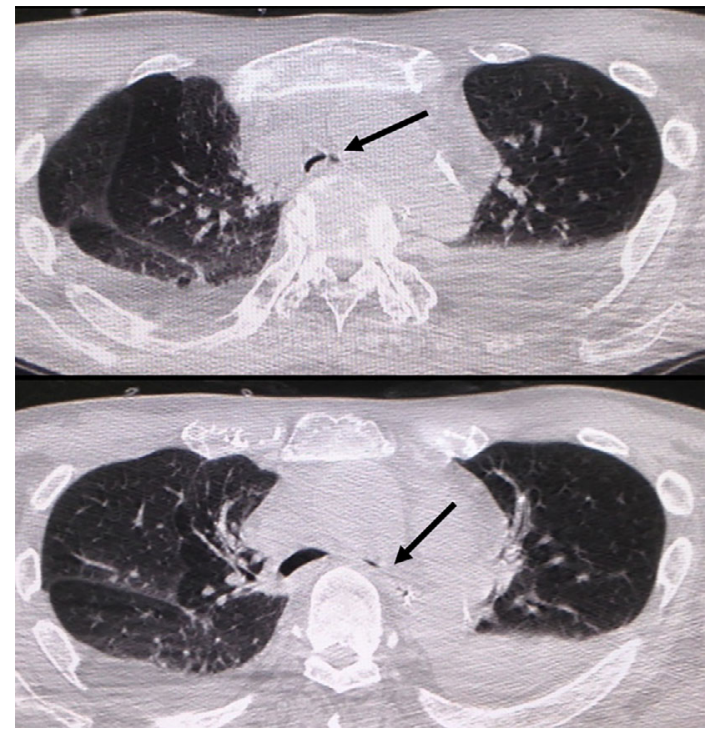

Figure. Chest computed tomography (CT) of this case. CT revealed that the trachea and left main bronchus were compressed by the thoracic spine and sternum.

of gigantism and acromegaly. After the operation, he developed pituitary dysfunction (requiring steroid and thyroxine replacement), postoperative epilepsy, steroid-induced diabetes mellitus and osteoporosis. He underwent right total hip replacement for coxarthrosis at 37 years of age. At 53 years of age, he became quadriplegic due to a cervical cord injury and required an apparatus for gate assistance. At 60 years of age, an abnormal mass in the right lung was confirmed, and this lesion was followed up on an outpatient basis. He did not have a history of an enlarged aorta, aortic tearing, dislocation of the lens of the eye or a family history of Marfan syndrome. Before this admission, the patient experienced dysphagia and normally consumed a liquid or soft food diet.

The findings of an arterial blood gas analysis before initial intubation (oxygen mask of $10 \mathrm{~L} / \mathrm{min}$ ) revealed a $\mathrm{pH}$ of 7.17, a $\mathrm{pCO}_{2}$ level of $74 \mathrm{mmHg}$, a $\mathrm{pO}_{2}$ level of $122 \mathrm{mmHg}$, a $\mathrm{HCO}_{3}^{-}$level of $27 \mathrm{mEq} / \mathrm{L}$ and a lactate level of $1.0 \mathrm{mg} / \mathrm{dL}$. Electrocardiogram showed right bundle branch block, and chest roentgen showed clear lung fields except for the abnormal lesion in the right lung. Enhanced computed tomography (CT) ruled out the existence of massive pulmonary embolism but indicated that the trachea and left main bronchus were compressed by the thoracic spine and sternum. After consultation with a respiratory physician and surgeon, we performed tracheotomy and inserted an Adjustfit tracheostomy tube (Fuji System Corporation, Tokyo, Japan) to maintain a long tracheal airway (Figure). He also required positive end-expiratory pressure to maintain his pulmonary function. When the patient attempted to breathe spontaneously through the tracheal tube, he showed retractions and frail chest-like movements with complaints of dyspnea in the supine position. He could occasionally breathe smoothly while in a sitting position. Permanent insertion of a tracheal stent was not recommended by respiratory physicians because this procedure could induce complete fatal obstruction of the tracheal airway. Accordingly, he was transferred to another hospital for thoracoplasty to achieve decompression of the trachea and left main bronchus. While waiting to undergo the operation, he died suddenly due to a lethal arrhythmia induced by pericarditis. An autopsy and pathological study failed to demonstrate any mechanical compression of the trachea.

\section{Discussion}

In the present case, a long tracheal tract and the main bronchus were compressed by hyperostosis and a thoracic spine and sternum; as such, simple tracheotomy was not effective. Scarpa et al. reported that arthropathy was the major cause of morbidity in cases of acromegaly compared with sex-, age-, and body mass index-matched healthy controls (16). In particular, a reduction in spinal mobility, alterations in the spinal profile and thoracic cage and features of diffuse idiopathic skeletal hyperostosis were significantly dominant in acromegalic patients. Accordingly, spinal deformity and the spine and sternum were found to compress the trachea in acromegalic patients.

The human body undergoes a variety of changes with age, including both morphological changes (e.g. increased thoracic kyphosis) and material changes (e.g. osteoporosis). Accordingly, the changes that occur with age in the present case may have resulted in the delayed onset of tracheal compression (17). However, in the present patient, resection of the ventral part of the thorax on autopsy, which was a decompressive procedure, failed to demonstrate compression of the trachea by the spine or sternum. This might be because the tracheal and bronchial cartilage is elastic; therefore, the decompression of the thoracic cage resulted in the restoration of the original shape of the lower airway. Grillo et al. also reported that the original shape of the trachea was restored after surgical procedures such as sternoplasty and sternal division (2). Accordingly, previous autopsies may have missed tracheal obstruction induced by thoracic deformity in acromegalic patients who died due to suffocation.

Physicians should focus on clearance of the tracheal airway using CT to determine the anatomical relationship between the trachea and surrounding structures in acromegalic patients suffering from dyspnea. In addition, as thoracoplasty is not simple to perform, an early diagnosis of acromegaly is mandatory to increase the chance of survival in such patients.

\section{The authors state that they have no Conflict of Interest (COI).}

\section{Financial Support}

Research funding, MEXT (The Ministry of Education,Culture, Sports, Science and Technology)-Supported Program for the Strategic Research Foundation at Private Universities 2015-2019 for the constitution of total researching system for comprehensive disaster medical management, corresponding to wide-scale disaster. 


\section{References}

1. Krucik G. What causes airway obstruction? 8 possible conditions. Healthline. [cited 2016 Apr 21] Abailable from: http://www.healthl ine.com/symptom/airway-obstruction

2. Grillo HC, Wright CD, Dartevelle PG, et al. Tracheal compression caused by straight back syndrome, chest wall deformity, and anterior spinal displacement: techniques for relief. Ann Thorac Surg 80: 2057-2062, 2005.

3. Donnelly LF, Bisset GS 3rd. Airway compression in children with abnormal thoracic configuration. Radiology 206: 323-326, 1998.

4. Andrews TM, Myer CM 3rd, Gray SP. Abnormalities of the bony thorax causing tracheobronchial compression. Int J Pediatr Otorhinolaryngol 19: 139-144, 1990.

5. Tanaka M, Watanabe Y, Fukushima K, et al. Fatal stenosis of trachea and main bronchus due to compression by the spine and sternum in three patients with severe motor and intellectual disabilities. No To Hattatsu 33: 347-350, 2001 (in Japanese, Abstract in English).

6. Kobayashi N, Tagawa T, Itagaki Y, et al. A severe motor and intellectual disabilities case of severe stenosis of trachea and main bronchus due to compression by the spine and sternum. Shonika Rinsho 53: 1419-1423, 2000 (in Japanese).

7. Matsuura $\mathrm{H}$, Ando S. A case of suffocation due to deformity of thorax complicating nocturnal hypoventilation. Suimin Iryo 8: 680-685, 2014 (in Japanese).

8. Takehisa M, Tatara K, Miyazaki T, et al. A case in which partial removal of the suprasternal region was effective in relieving tracheal stenosis caused by abnormal thoracic shape. IRYO 61: 554-
557, 2007 (in Japanese).

9. Tatekawa Y, Tojo T, Kanehiro H, et al. Multistage approach for tracheobronchomalacia caused by a chest deformity in the setting of severe scoliosis. Surg Today 37: 910-914, 2007.

10. Wright AD, Hill DM, Lowy C, et al. Mortality in acromegaly. Q J Med 39: 1-16, 1970.

11. Murrant NJ, Gatland DJ. Respiratory problems in acromegaly. J Laryngol Otol 104: 52-55, 1990.

12. Chappell WF. A case of acromegaly with laryngeal and pharyngeal symptoms. J Laryngol Rhinology Otol 1: 142, 1986.

13. Saussez S, Mahillon V, Chantrain G, et al. Acromegaly presented as a cause of laryngeal dyspnea. Auris Nasus Larynx 34: 541-543, 2007.

14. Cooper T, Dziegielewski PT, Singh P, et al. Acromegaly presenting with bilateral vocal cord immobility: case report and review of the literature. J Voice, in press.

15. Evans CC, Hipkin LJ, Murray GM. Pulmonary function in acromegaly. Thorax 32: 322-327, 1977.

16. Scarpa R, De Brasi D, Pivonello R, et al. Acromegalic axial arthropathy: a clinical case-control study. J Clin Endocrinol Metab 89: 598-603, 2004.

17. Kent R, Lee SH, Darvish K, et al. Structural and material changes in the aging thorax and their role in crash protection for older occupants. Stapp Car Crash J 49: 231-249, 2005.

The Internal Medicine is an Open Access article distributed under the Creative Commons Attribution-NonCommercial-NoDerivatives 4.0 International License. To view the details of this license, please visit (https://creativecommons.org/licenses/ by-nc-nd/4.0/).

(C) 2017 The Japanese Society of Internal Medicine http://www.naika.or.jp/imonline/index.html 